Jurnal Penelitian Bahasa dan Sastra Indonesia V1.i1 (1-12)

\title{
KONFLIK BATIN TOKOH ZAHRANA DALAM NOVEL CINTA SUCI ZAHRANA KARYA HABIBURRAHMAN ELSHIRAZY
}

\author{
Diyan Permata Yanda \\ Dosen Program Studi Pendidikan Bahasa dan Sastra Indonesia \\ STKIP PGRI Sumatera Barat \\ email: diyan_yanda@yahoo.com
}

\author{
Submitted :5-10-2016, Reviewed: 7-10-2016 Accepted:15-10-2016 \\ http://dx.doi.org/10.22202/jg.2015.v1i1.1164
}

\begin{abstract}
ABSTRACK
This article aims to reveal the structure of the novel and the inner conflict experienced Zahrana figures. Zahrana is a girl educated, intelligent, and achieving a dilemma when faced with the choice of pursuing goals, career, and marriage. Zahrana experienced inner conflict arises when there is a difference in her desire that want to continue education with the wishes of parents who want to get married. Her parents worried about her son would be called an old maid because never married. This concern stems from the view of society that a woman's primary duty is to be a mother to her children. Readers can reap the lessons of this novel with the existence of a series of character and his life journey.
\end{abstract}

Keyword: inner conflict, character, novel

\begin{abstract}
ABSTRAK
Artikel ini bertujuan untuk mengungkapkan struktur novel dan konflik batin yang dialami tokoh Zahrana. Zahrana adalah seorang cewek berpendidikan, cerdas, dan mencapai dilema ketika dihadapkan pada pilihan tujuan mengejar, karir, dan pernikahan. Zahrana mengalami konflik batin muncul ketika ada perbedaan dalam keinginannya yang ingin melanjutkan pendidikan dengan keinginan orang tua yang ingin menikah. Orangtuanya khawatir anaknya akan disebut perawan tua karena tidak pernah menikah. Kekhawatiran ini berasal dari pandangan masyarakat bahwa tugas utama seorang wanita adalah menjadi ibu bagi anak-anaknya. Pembaca dapat menuai pelajaran dari novel ini dengan adanya serangkaian karakter dan perjalanan hidupnya.
\end{abstract}

Kata kunci: konflik batin, tokoh, novel.

\section{PENDAHULUAN}

Keberadaan tokoh dalam sebuah cerita memberikan peranan penting dalam menyampaikan pesan cerita yang hendak disampaikan pengarang dalam sebuah karya sastra. Semi (1988:8) menyatakan bahwa karya sastra 
merupakan suatu bentuk dan hasil pekerjaan seni kreatif yang objeknya manusia dan kehidupannya dengan menggunakan bahasa sebagai mediumnya. Pengarang dapat mengambil ide cerita atau permasalahan yang dikemukakan dalam karya sastra berdasarkan pengalaman atau kenyataan yang sering dijumpai di tengah-tengah masyarakat.

Menarik atau tidaknya permasalahan yang disampaikan tergantung kepada kepiawaian pengarang dalam mengembangkan cerita sehingga cerita itu menjadi sesuatu yang hidup dan digemari masyarakat. Kehidupan masyarakat yang terdiri atas bermacam-macam strata sosial merupakan salah satu faktor yang dapat mempengaruhi pola pikir masyarakat dalam memandang sesuatu. Meskipun pada saat ini telah ada asumsi masyarakat tentang kesetaraan gender bahwa kedudukan laki-laki dan perempuan adalah sama, perempuan boleh bergerak maju seperti laki-laki, ternyata oleh sebagian masyarakat hal itu dianggap sebagai sesuatu yang tidak biasa.

Mengenai peranan perempuan ini sebenarnya telah dicanangkan oleh RA Kartini pada masanya untuk mempertahankan hak-hak perempuan agar memperoleh penghidupan dan kehidupan yang layak. Perempuan berhak memperoleh pendidikan setinggi-tingginya bukan hanya untuk di rumah sebagai seorang istri dan mengurusi dapur. Perempuan juga harus memiliki pendidikan untuk membina keluarganya. Dalam salah satu surat R.A Kartini kepada Prof. Anton dan Nyonya, 4 Oktober 1902 (Amnie, 2012) mengemukakan sebagai berikut.

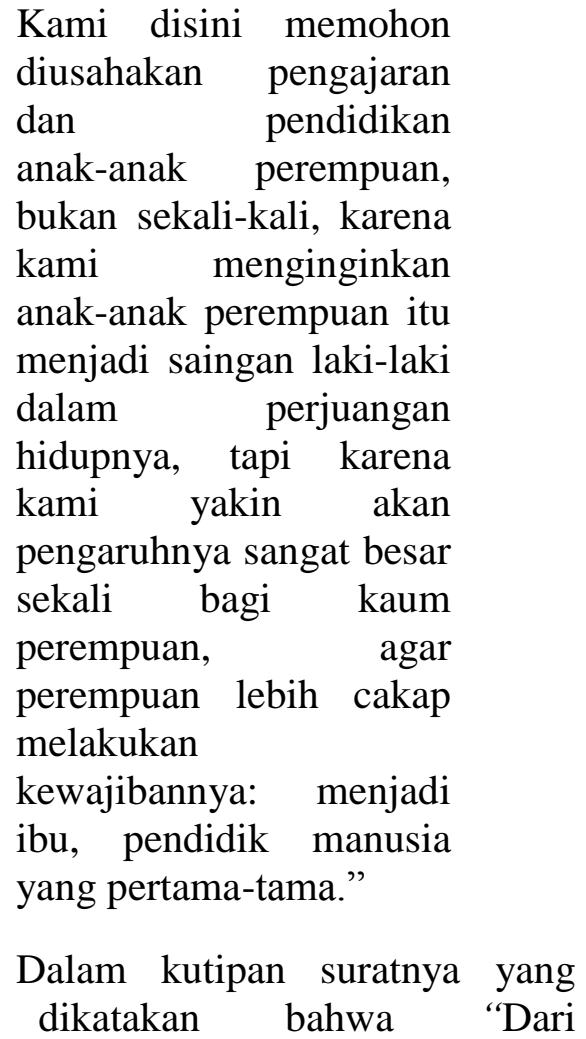
lain dikatakan bahwa "Dari perempuanlah manusia pertama-tama menerima pendidikan. Di pangkuan perempuanlah seseorang mulai belajar merasa, berpikir dan berkata-kata“. Perempuan memiliki peranan yang cukup berpengaruh untuk kemajuan bangsa. Dalam kehidupan modern seperti saat ini, telah banyak perempuan-perempuan Indonesia yang mengharumkan nama bangsa. Sesuai dengan pernyataan Arbiyanti (2010) tentang kata yang menginspirasi dari 
Kartini dalam suratnya yang lain sebagai berikut.

Ternyata dari masa ke masa kemajuan perempuan itu merupakan faktor penting dalam usaha memajukan bangsa. Kecerdasan pikiran penduduk Bumiputra tidak akan maju secara pesat bila perempuan ketinggalan dalam usaha itu. Perempuan sebagai pendukung peradaban.

Namun, dalam kehidupan bermasyarakat, perempuan tetaplah perempuan tanpa menanggalkan fungsinya sebagai seorang ibu. Adanya anggapan masyarakat bahwa pendidikan tinggi akan menyulitkan seorang perempuan mendapatkan jodoh atau pasangan hidup, sehingga banyak ditemukan para orangtua yang lebih memilih menikahkan anaknya diusia muda daripada harus menyekolahkan anaknya tinggi-tinggi. Jika sudah menikah, orangtua telah lepas tanggung jawab dalam membiayai anaknya karena sepenuhnya telah menjadi tanggung jawab suaminya.

Selain itu, adanya anggapan bahwa pendidikan tinggi perempuan akan membuat laki-laki merasa malu memiliki istri karena takut jika perempuan yang menjadi istrinya akan menguasai dalam kehidupan berumah tangga. Mereka gengsi karena memiliki pendidikan yang lebih rendah. Ternyata, asumsi itu semakin berkembang di masyarakat. Oleh karena itu, karya sastra yang dihasilkan selama ini berupaya memberikan manfaat kepada pembaca karena sifatnya yang menjelaskan fenomena-fenomena yang sangat dekat dengan kehidupan masyarakat. Melalui karya sastra pembaca dapat memperoleh pemikiran baru dalam kehidupan, karena selain menghibur karya sastra banyak memberikan nilai-nilai kehidupan yang berguna dalam menentukan pola pikir, gaya hidup, dan cara pandang terhadap fenomena yang terjadi dalam kehidupan.

Salah satu karya sastra yang paling digemari pembaca adalah novel. Novel adalah karya imajinatif yang mengisahkan sisi utuh problematika kehidupan seseorang atau beberapa orang tokoh. Kisah novel berawal dari kemunculan persoalan yang dialami oleh tokoh hingga tahap penyelesaiannya (Kosasih, 2008:54). Sebuah novel memunculkan tokoh-tokoh dengan karakteristik dan perwatakan yang berbeda-beda. Munculnya tokoh dengan kisah perjalanan hidup, secara tidak langsung dapat mempengaruhi kondisi psikologis para tokoh atau pelaku cerita lainnya. Kondisi kejiwaan yang dialami para tokoh dapat mengalami perubahan tergantung pada situasi yang mereka hadapi.

Salah seorang penulis yang terkenal dan banyak memanivestasikan kejiwaan dalam karyanya adalah Habiburrahman El Shirazy. Ia adalah novelis nomor satu Indonesia yang 
dinobatkan oleh Insani Universitas Diponegoro Semarang pada tahun 2008. Sastrawan terkemuka Indonesia ini juga dinobatkan oleh Harian Republika sebagai tokoh perubahan Indonesia 2007. Ia dilahirkan di Semarang Jawa Tengah, $\quad 30 \quad$ September 1976. Karya-karyanya banyak diminati tidak hanya di Indonesia, tetapi juga di mancanegara seperti Malaysia, Singapura, Brunei, Hongkong, Taiwan, dan Australia. Banyak kalangan menilai, karya-karya fiksinya dapat membangun jiwa dan menumbuhkan semangat berprestasi pembaca. Karya-karya Habiburrahman yang terkenal dalam bentuk kumpulan cerpen dan novel yaitu Ketika Cinta Berbuah Surga (2005), Pudarnya Pesona Cleopatra (2005), Ayat-ayat Cinta (2004, telah difilmkan), Di Atas Sajadah Cinta (2004, telah disinetronkan), Ketika Cinta Bertasbih 1 dan Ketika Cinta Bertasbih 2 (2007, telah difilmkan), Bumi Cinta (2010), Dalam Mihrab Cinta (2011, telah difilmkan), dan Cinta Suci Zahrana (2011). (Shirazy, 2011:277).

Novel-novel karya Habiburrahman El Shirazy memuat aspek psikologis, sebagai pengungkapan ekspresi kegelisahan jiwa dalam menjalani realita kehidupan sebagai perempuan. Salah satu novel karyanya yang berjudul Cinta Suci Zahrana sarat dengan permasalahan yang dialami seorang gadis yang tak kunjung menemukan jodohnya. Hal yang menjadi pokok permasalahan dalam novel ini adalah mengenai konflik batin tokoh Zahrana antara keinginannya, keinginan orangtuanya, dan pandangan sosial masyarakat terhadap perempuan berumur yang belum menikah. Tokoh utama dalam novel ini bernama Zahrana, seorang perempuan yang terlahir dari keluarga sederhana tetapi berpendidikan tinggi, cerdas, dan berprestasi.

Berdasarkan penjelasan di atas dapat disimpulkan betapa pentingnya pendidikan bagi seorang perempuan karena dari perempuanlah seorang anak mulai belajar. Pendidikan sangat penting bagi perempuan untuk membina keluarga dan mendidik anak-anaknya. Namun, bagaimana jadinya kalau perempuan lebih memprioritaskan pendidikan dan cita-citanya sementara mengabaikan rencana berumah tangga?

Berdasarkan permasalahan di atas, maka fokus masalah dalam hal ini lebih ditekankan kepada struktur novel dan konflik batin yang dialami oleh tokoh Zahrana dalam novel Cinta Suci Zahrana karya Habiburrahman El Shirazy. Secara terperinci, masalah-masalah yang akan dipaparkan dalam artikel ini adalah berikut ini. (1) Bagaimanakah struktur novel Cinta Suci Zahrana? (2) Bagaimanakah konflik batin yang dialami tokoh Zahrana? (3) Bagaimanakah sebab-sebab munculnya konflik batin yang dialami tokoh Zahrana? Artikel ini bertujuan memberikan penjelasan tentang hal-hal berikut ini. (1) Struktur novel Cinta Suci Zahrana. (2) Konflik batin yang dialami Zahrana. (3) Sebab-sebab munculnya konflik batin yang dialami Zahrana. 


\section{PEMBAHASAN}

Semi (1988:8) menyatakan bahwa karya sastra merupakan suatu bentuk dan hasil pekerjaan seni kreatif yang objeknya manusia dan kehidupannya dengan menggunakan bahasa sebagai mediumnya. Pengarang dapat mengambil ide cerita atau permasalahan yang dikemukakan dalam karya sastra berdasarkan pengalaman atau kenyataan yang sering dijumpai di tengah-tengah masyarakat. Novel Cinta Suci Zahrana karya Habiburrahman El Shirazy menceritakan tentang dilema seorang perempuan dalam menentukan pilihan hidup yang berakibat pada dirinya sendiri dan orang lain. Tokoh Zahrana dipandang sebagai seorang perempuan yang berpendidikan tinggi, cerdas, dan berprestasi. Zahrana menginginkan pendidikan tinggi dan prestasi sehingga keinginan untuk berumah tangga menjadi hal yang tidak terlalu dipusingkannya. Akan tetapi pada suatu hari keinginan untuk berumah tangga dan desakan dari orangtuanya menumbuhkan konflik tersendiri bagi tokoh Zahrana.

Struktur novel terdiri atas penokohan, tema, alur, pusat pengisahan, dan latar. Muhardi dan Hasanudin (1992:24) mengatakan bahwa penokohan termasuk ke dalam masalah penamaan, pemeranan, keadaan fisik, keadaan psikis, dan karakter. Ada beberapa metode penyajian watak tokoh atau metode penokohan, masing-masing dengan kelebihan dan kekurangannya, adakalanya pengarang melalui pencerita mengisahkan sifat-sifat tokoh, hasrat, pikiran, dan perasaannya, kadang-kadang dengan menyisipkan kilatan (allusion) atau komentar pernyataan setuju tidaknya akan sifat-sifat tokoh itu (Sudjiman, 1992:23).

Tokoh Zahrana adalah seorang gadis yang cerdas dan berprestasi. Hal ini dapat dibuktikan dengan kutipan di bawah ini.

$\begin{array}{lr}\text { "Ia diundang ke Beijing } \\ \text { untuk menerima } \\ \text { penghargaan } & \text { atas } \\ \text { karya-karya } & \text { dan } \\ \text { prestasinya di bidang } & \text { biding } \\ \text { arsitektur. Artikel yang ia } \\ \text { tulis di jurnal ilmiah yang } \\ \text { diterbitkan oleh RMIT } \\ \text { Melbourne, Australia } \\ \text { mendapat apresiasi yang } \\ \text { sangat luas dari para } \\ \text { pakar arsitektur dunia. } \\ \text { Dan puncaknya ia } \\ \text { diundang ke Beijing } \\ \text { untuk diberi penghargaan } \\ \text { level internasional oleh } \\ \text { School Of Architecture, } \\ \text { Tsinghua } \\ \text { sebuah University, } \\ \text { ternama China. Tidak } \\ \text { mudah universitas } \\ \text { penghargaan mendapat } \\ \text { pengakuan seprestisius } \\ \text { itu” (Shirazy, 2011:2). }\end{array}$

Zahrana adalah orang yang ambisius dan gigih dalam mencapai 
cita-citanya. Perhatikan juga kutipan berikut ini.

"Ia masih ingat, saat ini teman-temannya yang tahu ia melakukan hal itu, kuliah di dua jurusan yang berbeda, di universitas yang beda, ia dianggap gila. ... tetapi dengan kesungguhan dan kerja kerasnya, hal yang dianggap gila oleh temannya itu dapat ia lalui dengan baik... dan ia berhasil" (Shirazy, 2011:9).

Pada kutipan di atas terlihat bahwa Zahrana adalah seorang yang ambisius, perhatikan juga kutipan berikut ini.

"Ia telah meneguhkan Azzamnya bahwa ia akan menambah dedikasinya dalam mendidik anak bangsa, dan ia harus mengambil S3 paling lambat dua atau tiga tahun ke depan...". (Shirazy, 2011:84).

Muhardi dan Hasanuddin (1992:38) mengatakan bahwa tema adalah inti permasalahan yang hendak dikemukakan pengarang dalam karyanya. Tema itu kadang-kadang didukung pelukisan latar, di dalam karya yang lain tersirat di dalam lakuan tokoh, atau di dalam lakuan tokoh (Sudjiman, 1992:51). Berkaitan dengan hal tersebut, tema yang terdapat dalam novel Cinta Suci Zahrana karya Habiburrahman El Shirazy adalah tentang konflik batin atau dilema untuk menentukan pilihan. Hal ini dapat dibuktikan dengan kutipan di bawah ini.

"Ia belum bisa mengambil keputusan. Kata-kata Wati selalu terngiang-ngiang di telinganya. Ia nyaris memutuskan untuk menerima saja lamaran Pak Karman. Namun jika ia teringat apa yang dilakukan Pak Karman pada beberapa mahasiswi yang dikencaninya, diam-diam ia tak mungkin memaafkan" (Shirazy, 2011)

Perhatikan juga kutipan berikut ini. “... yang justru ia risaukan, jika ia ijin untuk belajar ke luar negeri, apakah ayah dan ibunya akan mengijinkan" (Shirazy, 2011:84).

Kemudian kutipan berikut ini.

"Ia belum juga mendapatkan jodohnya. Setelah mendapat tawaran dari Pak Didik, sudah dua orang yang maju. Tapi entah kenapa 
Jurnal Penelitian Bahasa dan Sastra Indonesia V1.i1 (1-12)

ia tidak sreg. Hatinya

belum cocok..."

(Shirazy, 2011:227).

Dari kutipan di atas tergambar bahwa tema yang disampaikan adalah dilema atau konflik batin yang dialami seorang perempuan untuk menentukan pilihan.

Menurut Semi (1988:43), alur atau plot adalah struktur rangkaian kejadian dalam cerita yang disusun sebagai sebuah interrelasi fungsional yang sekaligus menandai urutan-urutan bagian dalam keseluruhan fiksi. Plot atau alur hendaknya diartikan tidak hanya sebagai peristiwa-peristiwa yang diceritakan dengan panjang lebar dalam suatu rangkaian tertentu tetapi juga merupakan penyusunan yang dilakukan oleh penulisnya mengenai peristiwa-peristiwa tersebut berdasarkan hubungan-hubungan kausalitasnya (Sayuti, 2000:30). Senada dengan itu, Stanton (2012:26) mengatakan bahwa alur merupakan bagian dari rangkaian peristiwa-peristiwa dalam sebuah cerita yang terhubung secara kausal, yaitu peristiwa yang menyebabkan atau dampak dari berbagai peristiwa lain dan tidak dapat diabaikan karena akan berpengaruh pada keseluruhan karya. Alur dalam novel ini adalah alur maju mundur, hal ini terlihat sewaktu Zahrana sedang berada dalam pesawat ke Beijing ia teringat dengan Gugun yang pernah ingin menikah dengannya, kemudian diceritakan lagi peristiwa setelah ia tiba di Beijing.
Semi (1988:57) mengatakan bahwa pusat pengisahan adalah posisi dan penempatan diri pengarang dalam ceritanya, atau dari mana ia melihat peristiwa-peristiwa yang terdapat dalam ceritanya itu. Sudut pandang atau pusat pengisahan (point of view) dipergunakan untuk menentukan arah pandang pengarang terhadap peristiwa-peristiwa di dalam cerita sehingga tercipta suatu kesatuan cerita yang utuh (Sayuti, 2000:158). Pusat pengisahan dalam novel ini adalah pengarang sebagai orang ketiga.

Semi (1988:46) mengatakan bahwa latar atau tandas tumpu (setting) cerita adalah lingkungan tempat peristiwa terjadi. Latar adalah lingkungan yang melingkupi sebuah peristiwa dalam cerita, semesta yang berinteraksi dengan peristiwa-peristiwa yang sedang berlangsung (Stanton, 2012:35). Latar dalam novel Cinta Suci Zahrana ini adalah di Beijing, Daerah Temanggung, Semarang, dan Solo. Hal ini dapat dibuktikan dengan kutipan di bawah ini.

"Pengalamannya selama tiga hari di Beijing sangat membekas". (Shirazy, 2011:81).

Perhatikan juga kutipan berikut ini.

"Suatu hari Lina mengajak Zahrana mengunjungi seorang Kiai yang sudah tua di 
ini.

Daerah Temanggung”

(Shirazy, 2011:215).

Perhatikan juga kutipan berikut

"Sore itu di kota

Semarang kembali gelap.

Langit hitam pekat.

Langit berdenyar-denyar.

Bunyi petir menggelegar"

(Shirazy, 2011:171).

Perhatikan juga kutipan

berikut ini.

"Satu jam lagi
pesawatnya
mendarat di Solo"

(Shirazy, 2011:81).

Pentingnya pendidikan bagi kaum perempuan diharapkan dapat membantu mereka dalam membina kehidupan berumah tangga yang lebih baik, tidak ada larangan bagi kaum perempuan untuk memperoleh pendidikan setinggi-tingginya maupun untuk berprestasi secara akademik. Hal ini akan menjadi masalah jika pendidikan menjadi alasan untuk menunda-nunda pernikahan dan bertentangan dengan pandangan yang telah lama dianut masyarakat. Selain itu, juga akan menjadi semacam gunjingan atau hinaan di masyarakat jika ada gadis yang sudah berumur tetapi belum menikah. Hal inilah yang dipaparkan dalam novel Cinta Suci Zahrana, ada permasalahan-permasalahan yang menimbulkan konflik batin di dalamnya. Konflik batin adalah konflik yang terjadi dalam hati, jiwa seorang tokoh (atau: tokoh-tokoh) cerita. Jadi, ia merupakan konflik yang dialami manusia dengan dirinya sendiri, ia lebih merupakan perasaan intern seorang manusia (Nurgiyantoro, 2010: 124). Selanjutnya, munculnya konflik batin merupakan akibat pertentangan dari id, ego, dan super ego. Id sebagai pemberi dorongan, ego merupakan pikiran rasional, sedangkan super ego sebagai pengendali yang berisi sistem nilai dan norma yang berlaku di kalangan masyarakat sekitar.

Tokoh Zahrana yang bernama lengkap Dewi Zahrana dalam novel Cinta Suci Zahrana karya Habiburrahman El Shirazy digambarkan sebagai seorang gadis berprestasi yang mengalami konflik batin saat dihadapkan pada pilihan mengejar cita-cita, karir atau berumah tangga. Konvensi sosial masyarakat kita berpandangan bahwa perempuan itu lumrahnya adalah di rumah, menjadi istri, menjadi ibu, dan mengurus rumah tangga. Setinggi apapun pendidikan, sebanyak apapun prestasi yang diraih, belum disebut sempurna seorang perempuan jika belum menikah dan belum dapat melahirkan seorang generasi penerus keluarga, bangsa, dan negara. Selain itu, menjadi fitnah di masyarakat dan menimbulkan image negatif bagi perempuan sebagai perawan tua, dan itu dianggap mempermalukan keluarga.

Pengarang menampilkan tokoh Dewi Zahrana sebagai sosok gadis 
ambisius dan memiliki talenta luar biasa dalam bidang akademik. Ia terlahir dari keluarga biasa-biasa, ayahnya seorang PNS golongan rendah di kelurahan. Sebenarnya ayahnya ingin agar Zahrana masuk pesantren dan lulus menjadi sarjana yang hafal Al-Quran, agar kelak bisa menjadi seorang guru. Namun, Zahrana lebih memilih melanjutkan pendidikan ke SMA, ia harus berpura-pura sakit agar diizinkan oleh ayahnya, baginya profesi menjadi guru tidak menantang. Ia memiliki ambisi yang luar biasa untuk mengunjungi tempat-tempat indah di luar negeri, Oleh karena itu, akhirnya ia memilih jurusan arsitektur. Zahrana berhasil menyelesaikan S1 di Fakultas Teknik UGM Jogjakarta dan S2 di ITB.

Zahrana adalah mahasiswi yang selalu mendapat predikat terbaik di kampusnya, hingga akhirnya dua bulan setelah diwisuda, Ia mendapat tawaran untuk menjadi staf pengajar di UGM. Ia bahagia sekali, namun kedua orangtuanya tidak mengizinkan karena takut berpisah jauh dengan anak semata wayangnya. Oleh karena dorongan ingin menunjukkan bakti pada orangtua, Zahrana menolak tawaran tersebut dan mengajar di salah satu universitas swasta di Kota Semarang dan tidak mengambil S3. Dengan demikian, Ia tetap dapat tinggal bersama orangtuanya.

Nama Zahrana mendunia karena karya tulisnya dimuat di jurnal ilmiah RMIT Melbourne. Dari karya tulis itu, Zahrana meraih penghargaan dari Tshinghua University, sebuah universitas ternama di China. Ia pun terbang ke negeri Tirai Bambu untuk menyampaikan orasi ilmiah. Di hadapan puluhan profesor arsitek kelas dunia, ia memaparkan arsitektur bertema budaya. Yang ia tawarkan arsitektur model kerajaan Jawa-Islam dahulu kala. Dari Tshinghua University, Zahrana mendapat tawaran beasiswa untuk studi S3 di samping mendapat tawaran pengerjaan sebuah proyek besar. Namun, semacam permasalahan bergelayut dipikirannya karena orangtuanya bersikap dingin padanya dan tidak ikut mengantar ke bandara.

Di tengah kesuksesan prestasi akademiknya, Zahrana malah menjadi bahan kecemasan kedua orangtuanya. Kecemasan itu lantaran Zahrana belum juga menikah diusianya yang sudah kepala tiga. Sudah banyak laki-laki yang meminangnya, namun Zahrana menolaknya dengan halus. Di sinilah konflik batin Zahrana mulai timbul, antara menuruti keinginan orangtua atau mengejar cita-cita. Meski tidak otoriter, kedua orangtua Zahrana berharap anak satu-satunya itu segera menikah dan memiliki keturunan. Sebagai orangtua yang sudah renta, khawatir semasa hidupnya tidak sempat menyaksikan Zahrana bersuami dan menimang cucu. Apalagi bila melihat anak-anak tetangga seusia Zahrana, mereka sudah memiliki anak dua bahkan tiga. Sebenarnya dalam jiwa perempuan Zahrana, bukan tidak menghiraukan keinginan berumah tangga. Tetapi logika analitisnya selalu berargumen, menikah hanya 
menunda-nunda sukses bahkan bisa menghalangi kesuksesan.

Puncak konflik batin Zahrana ketika dilamar oleh seorang duda yang merupakan atasannya sendiri. Ia dilamar dekannya, begitu kembali dari Thinghua University sehabis menerima penghargaan. Dengan tegas, Zahrana tidak menerima lamaran atasannya itu meski orangtuanya kecewa. Alasan Zahrana semata-mata persoalan moral atasannya yang terkenal suka meminta setoran kepada mahasiswa bila ingin nilai bagus bahkan suka bermain cinta dengan mahasiswanya sendiri. Di samping alasan moral, Zahrana tak mungkin menerima lamaran atasanya yang berusia kepala lima.

Akibat menolak lamaran itu, Zahrana akan dipecat secara tidak hormat. Tetapi Zahrana mendahului mengajukan pengunduran diri. Ia benar-benar hengkang dari kampus itu dan memilih mengajar di sebuah sekolah kejuruan teknik. Pasca lamaran, Zahrana sadar, ia harus cepat-cepat bersuami. Hati Zahrana berargumen lain, bisa saja dirinya melanjutkan cita-cita di dunia akademik meski sudah bersuami. Ia pun minta saran kepada pimpinan pondok pesantren yang masih saudara jauh teman akrabnya. Oleh pimpinan pondok pesantren Zahrana dipertemukan dengan seorang pemuda yang dari sisi pekerjaan kurang prestisius. Pemuda itu pedagang kerupuk keliling dan Zahrana merasa cocok. Ia bertekad mengabdikan hidupnya kepada Allah melalui ibadah dalam rumah tangga. Kedua belah keluarga menyiapkan pesta pernikahan sederhana.

Zahrana menyiapkan gaun pengantin. Bahagia sekali hati Zahrana. Ia meyakinkan diri tak lama lagi akan bersuami yang sholeh. Ia membayangkan esok hari, kisah penantian ini akan segera berganti. Namun, bayangan itu sirna seketika saat menerima kabar calon suaminya meninggal, tertabrak kereta api yang tak jauh dari perkampungan. Kejadian itu disusul pula dengan kematian ayahnya akibat serangan jantung karena tidak tahan menghadapi berbagai permasalahan yang terjadi. Saat itu pula Zahrana merasa sudah mati. Bayangan indah kini berganti dengan kabut tebal yang dipenuhi hantu kematian yang siap mencabik-cabik dirinya. Bunga-bunga cinta di hatinya, kini berganti dengan bunga kematian. Langitpun runtuh dan serasa menindihnya. Zahrana pingsan beberapa kali hingga dilarikan ke rumah sakit. Beruntung Zahrana masih kuat melanjutkan hidup.

Beberapa hari setelah peristiwa itu, ia hanya di rumah sambil menekuri diri. Sahabat-sahabat dan kerabatnya banyak yang berdatangan untuk sekedar mengucapkan duka cita termasuk teman-teman dan atasannya di kampus tempat ia dulu mengajar. Salah seorang penjenguk, dokter perempuan yang sempat mengobatinya di rumah sakit. Perempuan itu ternyata ibunya mahasiswa bernama Hasan yang skripsinya sempat dia bimbing. Rupanya kedatangan ibu dokter ini sekaligus 
Jurnal Penelitian Bahasa dan Sastra Indonesia V1.i1 (1-12)

mengobati luka cinta Zahrana. Ibu dokter ternyata mengabarkan, anaknya, Hasan, berniat menikahinya.

Betapa kaget dan bahagianya Zahrana. Seolah tak peracaya dengan nasibnya yang begitu bergelombang. Meski ragu menerima lamaran itu, Zahrana menyampaikan satu syarat. Bila anak ibu dokter benar meminangnya, ia minta agar pernikahannya nanti malam setelah shalat tarawih. Ia sangat trauma dengan tragedi yang menimpa satu malam menjelang pernikahannya dulu. Setelah dialog cukup panjang, tawaran itu diterima ibu dokter. Tepat jam tujuh malam, mereka melangsungkan pernikahan suci di masjid yang disaksikan para jamaah shalat tarawih. Malam pertama bulan Ramadhan yang indah menandakan berakhirnya penderitaan Zahrana. Ia menyempurnakan hidupnya dengan mencurahkan cinta sucinya. Setelah menikah, Dewi Zahrana masih akan melanjutkan studi S3 nya, sementara suaminya meneruskan studi S2.

\section{KESIMPULAN}

Berdasarkan analisis struktural dapat diuraikan hal-hal berikut ini. (1) Tokoh dalam novel Cinta Suci Zahrana digambarkan melalui cerita yang disampaikan pengarang dalam novel. (2) Latar tempat berada di Indonesia, seperti Yogyakarta dan Semarang serta beberapa tempat di China seperti tembok besar cina dan Tsinghua University Cina. (3) Sudut pandangan pengarang adalah sudut pandang orang ketiga. Konflik batin yang dialami oleh tokoh Zahrana disebabkan oleh berbenturannya keinginannya dengan keinginan kedua orangtua yang menghendakinya segera menikah. Sementara Ia masih begitu berambisi untuk melanjutkan pendidikannya sampai jenjang S3. Hal seperti ini membuat Zahrana mengalami konflik baik dengan dirinya sendiri maupun dengan orang lain di sekitarnya.

Setelah menghadapi persoalan yang begitu rumit, akhirnya Zahrana menemukan jodohnya di usia 34 tahun. Ia akhirnya menikah dengan Hasan yang merupakan mahasiswanya sendiri yang pernah ia bimbing menyelesaikan skripsi di salah satu universitas swasta di Kota Semarang. Setelah mereka menikah, mereka sama-sama melanjutkan pendidikan kembali. Zahrana melanjutkan S3, sementara suaminya Hasan melanjutkan S2.

Dari kesimpulan di atas, saran yang dapat diberikan adalah untuk melakukan sesuatu haruslah dimulai dengan perencanaan yang matang. Hidup ini harus penuh dengan keseimbangan agar saat kita menginginkan sesuatu, kebutuhan yang lain tidak terabaikan. Melanjutkan pendidikan hingga tingkatan yang setinggi-tingginya seharusnya tak menghalangi sunat rasul untuk menjalani kehidupan berumah tangga. Mengejar target untuk dunia harus diseimbangkan dengan mengejar target untuk kehidupan akhirat. Serentetan kisah perjalanan hidup yang dialami baik suka maupun duka haruslah 
dihadapi dengan sabar dan penuh tawakkal. Jangan hanya mementingkan diri sendiri untuk memenuhi ambisi dunia yang menggebu-gebu, karena kehidupan kita terikat dengan orang lain. Ada masanya kita pun harus memikirkan orang-orang di sekitar kita. Seperti yang digambarkan dalam Novel Cinta Suci Zahrana, bahwa ada kedua orangtua yang harus diperhatikan keinginannya selain usaha memenuhi kepentingan pribadi.

\section{DAFTAR PUSTAKA}

Amnie, Erlida. 2012. Dan Kartini pun Memilih Islam. http//:artkel/dan-kartini-pun-mem ilih-islam-sungguh.html. diunduh tanggal 1 November 2012.

Arbiyanti. 2010. Inspirasi dari Kartini. http//:artkel/Inspirasi dari R.A Kartini «Here's to LIFE! Cheers -).htm. diunduh tanggal 1 November 2012.

Shirazy, Habiburrahman El. 2011. Cinta Suci Zahrana. Jakarta: Ihwah Publishing House.

Kosasih, E. 2008. Apresiasi Sastra Indonesia: Puisi, Prosa, Drama. Jakarta: Nobel Edumedia.
Muhardi dan Hasanuddin. 1992. Prosedur Analisis Fiksi. Padang: IKIP Padang Press.

Nurgiyantoro, Burhan. 2010. Teori Pengkajian Fiksi. Yogyakarta: Gajah Mada University Press.

Sayuti, Suminto. 2000. Berkenalan dengan Prosa Fiksi. Yogyakarta: Gama Media.

Semi, Atar. 1988. Anatomi Sastra. Padang: Angkasa Raya.

Stanton, Robert. 2012. Teori Fiksi Robert Stanton. Terjemahan Sugihastuti dan Irsyad. Yogyakarta: Pustaka Pelajar.

Sudjiman, Panuti. 1992. Memahami Cerita Rekaan. Bandung: Dunia Pustaka Jaya. 